\title{
Covid-19: Scotland recommends face coverings, but England does not follow suit
}

\author{
Elisabeth Mahase
}

The BMJ

The Scottish government has recommended that the public wear face coverings when in enclosed public spaces where social distancing is difficult, such as in food shops.

First minister Nicola Sturgeon emphasised that the new recommendation referred to fabric face coverings rather than medical grade masks and that, although evidence was limited, face covering might stop people with asymptomatic covid-19 from spreading the virus unknowingly.

After the announcement England's health secretary, Matt Hancock, said that the UK government had not changed its position from not recommending face coverings, arguing that the evidence was "weak."

New guidance from the Scottish government on face coverings states, "The evidence on the use of face coverings is limited, but there may be some benefit in wearing a facial covering when you leave the house and enter enclosed spaces, especially where physical distancing is more difficult and where there is a risk of close contact with multiple people you do not usually meet. "Examples include, traveling on public transport or entering a food shop where it is not always possible to maintain a two metre distance from another customer. There is no evidence to suggest there might be a benefit outdoors, unless in an unavoidable crowded situation, where there may be some benefit."

The guidance also outlines how to safely apply and wash face coverings.

\section{Evidence}

Speaking at a briefing on 28 April, Sturgeon said, "The benefit comes mainly in cases where someone may have the virus but is not aware of that because they are not experiencing any symptoms and are therefore not isolating completely. Wearing a face covering in these circumstances may reduce the chance of that person transmitting the virus on to others."

She added that, as the "evidence is relatively weak," face coverings would not be mandatory or enforced, although "we will be keeping that under review as we go into future phases of managing and tackling the pandemic."
She also recognised that some people might have reasons for not wearing face coverings, such as those with asthma, and said that the recommendation did not apply to children under the age of 2 .

Hancock said at another briefing later in the day, "On face masks we are guided by the science, and the UK government position hasn't changed, not least because the most important thing people can do is the social distancing ... As opposed to the weak science on face masks, there is very clear science on social distancing. That is our absolute priority in terms of the message to the public."

Angela MacLean, the government's deputy chief scientific adviser, said that the UK's Scientific Advisory Group for Emergencies (SAGE) had looked at the issue and concluded that "the answer is clear: the evidence is weak and the effect is small."

This comes after a group of researchers including Trisha Greenhalgh, professor of primary care health sciences at the University of Oxford, argued in The BMJ that the public should start wearing face masks as a precautionary measure. ${ }^{2}$

The researchers wrote, "In the face of a pandemic the search for perfect evidence may be the enemy of good policy. As with parachutes for jumping out of aeroplanes, it is time to act without waiting for randomised controlled trial evidence ... Masks are simple, cheap, and potentially effective.

"We believe that, worn both in the home (particularly by the person showing symptoms) and also outside the home in situations where meeting others is likely (for example, shopping, public transport), they could have a substantial impact on transmission with a relatively small impact on social and economic life."

1 Coronavirus (COVID-19): public use of face coverings. 28 Apr 2020. https://www.gov. scot/publications/coronavirus-covid-19-public-use-of-face-coverings/.

2 Greenhalgh T, Schmid MB, Czypionka T, Bassler D, Gruer L. Face masks for the public during the covid-19 crisis. BMJ 2020;369:m1435. 10.1136/bmj.m1435 32273267

Published by the BMJ Publishing Group Limited. For permission to use (where not already granted under a licence) please go to http://group.bmj.com/group/rights-licensing/ permissions 